\title{
Rádios comunitárias no Brasil: entre a clandestinidade e a relevância social
}

Community radios in Brazil: between clandestinity and social relevance

Radios comunitarias en Brasil: entre la clandestinidad y la relevancia social

Eliene SANTOS, Brasil

Universidade Federal de Ouro Preto / eliene.comunica@gmail.com

Nair PRATA, Brasil

Universidade Federal de Ouro Preto / airprata@uol.com.br

Rafael MEDEIROS, Brasil

Universidade Federal de Ouro Preto / rfmedeiros13@gmail.com

Chasqui. Revista Latinoamericana de Comunicación

N. ${ }^{\circ}$ 140, abril - julio 2019 (Sección Monográfico, pp. 129-146)

ISSN 1390-1079 / e-ISSN 1390-924X

Ecuador: CIESPAL

Recibido: 27-02-2019/Aprobado: 10-07-2019 


\section{Resumen}

As primeiras rádios comunitárias surgiram no Brasil na década de 1980 como uma vertente de diversos movimentos de transmissões radiofônicas ilegais que aconteceram a partir dos anos 1970 sob inspiração das chamadas rádios piratas europeias. Embora já inseridas na legislação específica para os serviços de radiodifusão, ainda existem muitas rádios funcionando ilegalmente no país. Este trabalho verifica o panorama atual do rádio comunitário no Brasil evidenciando seu surgimento clandestino e buscando suas especificidades através do estudo de caso de uma rádio com características de emissora comunitária que funciona clandestinamente há quase duas décadas no interior do país.

Palavras chave: rádios comunitárias; rádios ilegais; relevância social; estudo de caso

\section{Abstract}

The first community radios began to emerge in Brazil in the 1980s as a part of the illegal radio broadcasts that occur from the 1970s under the inspiration of the so-called European pirate radios. You are already included in the legislation for broadcasting services; in addition, there are many radios in activity illegally in the country. The work verifies the current panorama of the radio in Brazil evidencing its clandestine appearance and its specificities through the case study of a radio with characteristics of emission that operated clandestinely for almost two decades in the interior of the country.

Keywords: community radios; illegal radios; social relevance; case study

\section{Resumen}

Las primeras radios comunitarias surgieron en Brasil en la década de 1980 como una vertiente de diversos movimientos de transmisiones radiofónicas ilegales que ocurrieron a partir de los años 1970 bajo la inspiración de las llamadas radios piratas europeas. Aunque ya están incluidas en la legislación específica para los servicios de radiodifusión, todavía existen muchas radios que funcionan ilegalmente en el país. Este trabajo verifica el panorama actual de la radio comunitaria en Brasil evidenciando su surgimiento clandestino y buscando sus especificidades a través del estudio de caso de una radio con características de emisora comunitaria que funciona clandestinamente hace casi dos décadas en el interior del país.

Palavras-clave: radios comunitarias; radios ilegales; relevancia social; estudio de caso 


\section{Introdução}

Como um meio em constante transformação, o rádio se apresenta em diferentes formatos, com emissoras de variegadas configurações e objetivos. A radiodifusão no Brasil foi inaugurada no início do século XX com características educativas, com emissoras que objetivavam contribuir para o desenvolvimento cultural e formativo do país. O rádio se desenvolveu aos poucos, as emissoras cresceram, muitas delas abandonaram os objetivos iniciais e fizeram do meio um negócio lucrativo.

A partir da popularização do meio e do aparecimento de novas rádios foi necessário o controle específico dos serviços de radiodifusão. As primeiras legislações que versavam sobre o tema datam ainda da década de 1920, ainda na fase amadora do rádio brasileiro. Na década de 1930 foram editados os primeiros decretos que tratavam a radiodifusão como atividade profissional, permitindo $o$ uso comercial do meio e regulamentando a publicidade.

Embora muitas emissoras já tenham surgido com base na legislação específica, outras rádios apareceram à margem do controle estatal e, rapidamente, foram alcunhadas depreciativamente como "piratas". Seguindo um movimento mundial de rádios clandestinas, as rádios livres começaram a se formar no Brasil na década de 1970 e, desse movimento, surgiram as emissoras comunitárias no começo dos anos 1980.

Durante cerca de 20 anos as rádios comunitárias funcionaram de maneira ilegal no Brasil, não sendo amparadas ou controladas por nenhuma legislação específica. Apenas em 1997 passou a vigorar a lei que instituiu oficialmente o serviço de radiodifusão comunitária. Desde então, quase cinco mil emissoras receberam outorga de rádio comunitária, sendo autorizadas a veicular seus conteúdos através de transmissores de baixa potência para um público restrito às comunidades onde estão inseridas.

Seja por meio da linguagem utilizada, da proximidade com a população, dos assuntos abordados, do uso de expressões e sotaques próprios da comunidade, essas emissoras conseguem atender aos interesses e necessidades da audiência.

Este trabalho apresenta um panorama atual das rádios comunitárias no Brasil, apontando para o seu surgimento clandestino e busca as especificidades dessas emissoras irregulares a partir de estudo de caso baseado na Rádio Paraíso, emissora com características de rádio comunitária e que funciona há 17 anos, sem autorização, no interior de Minas Gerais. Os métodos utilizados para a investigação se baseiam em escuta sistematizada da programação da emissora, visitas à sua sede e entrevista semiestruturada com o idealizador da rádio.

\section{O surgimento das rádios comunitárias no Brasil}

As rádios comunitárias surgiram no Brasil como uma vertente de diversos movimentos de transmissões radiofônicas ilegais que aconteceram a partir 
da década de 1970 sob inspiração das chamadas rádios piratas europeias. Esses movimentos se articularam nomeadamente como rádios livres, rádios comunitárias ou rádios piratas a depender de suas especificidades de alcance, programação e objetivos.

Embora hoje o nome seja usado para se referir a qualquer tipo de rádio ilegal, as rádios piratas tiveram início na Grã-Bretanha do final dos anos 1950 "quando vários barcos equipados com transmissores navegavam pelos mares apontando suas antenas para terras inglesas" (Sousa, 1997, p. 20), por isso a nomenclatura "piratas". No Brasil, as emissoras piratas também foram criadas com o objetivo de obter lucro através da exploração comercial do rádio. É essa a principal diferença das piratas para as comunitárias e livres: enquanto as primeiras "vêem o rádio como um negócio lucrativo e, em termos de programação, não apresentam nada de novo em relação à programação das rádios oficiais" (ibid.), as rádios livres têm caráter ideológico, libertário, auto gestionário e objetivam contestar o monopólio dos modelos de programação das rádios oficiais.

A primeira rádio livre do Brasil foi criada por jovens da Vila Nossa Senhora de Fátima, região periférica da cidade de Belo Horizonte, Minas Gerais, no ano de 1981. Chamada de Rádio Favela, a emissora surgiu da "necessidade dessas pessoas possuírem um veículo de comunicação adequado à sua cultura, ao seu cotidiano" (Andriotti, 2004, p. 20), sendo uma alternativa às rádios que não representavam a realidade de uma comunidade localizada distante das áreas centrais da cidade. Hoje a Rádio Favela, autorizada a funcionar legalmente como emissora educativa, se apresenta como rádio comunitária e opera com transmissor de baixa frequência.

As características e os objetivos das rádios livres se assemelham muito aos das comunitárias, uma vez que essas "nascem a partir da organização das rádios livres como movimento e da disseminação destas entre as classes populares, que passam a fazer uso do rádio como veículo de entretenimento e organização social" (Sousa, 1997, p. 21). Desde o começo foram claros os objetivos de democratizar a comunicação e informar uma população invisibilizada pelos meios tradicionais sobre temas próximos de sua realidade. Entre outras definições entendidas nos trabalhos específicos sobre a área, o presente artigo recorre à Cicilia Peruzzo (2010) para destacar a mídia comunitária como "aquela gerada no contexto de um processo de mobilização e organização social dos segmentos excluídos (e seus aliados) da população com a finalidade de contribuir para a conscientização e organização de segmentos subalternos da população visando superar as desigualdades e instaurar mais justiça social” (Peruzzo, 2010, p. 8-9), além de buscar o desenvolvimento das comunidades, não visar lucro, ter alcance limitado, ter conteúdo produzido por setores da comunidade.

A legislação brasileira para radiodifusão data da década de 1960 e não acompanha de forma efetiva as variegadas mudanças ocorridas no setor. A existência das rádios comunitárias por tantos anos como irregulares é uma demonstraçãodamorosidadedalegislaçãonoque concerneàstelecomunicações. 
Apenas em 1998 foi promulgada lei específica sobre os serviços de radiodifusão comunitária: a Lei 9.612, que instituiu o serviço de radiodifusão comunitária no Brasil, surgiu da disseminação das emissoras clandestinas e da dificuldade de controle e fiscalização dessas rádios ilegais, sobretudo em zonas periféricas.

Embora imponha uma série de medidas de adaptação, a legislação teve como base o modo de funcionamento das rádios já existentes e evidencia, entre outras funções, que as emissoras comunitárias devem ter por finalidade

I - Dar oportunidade à difusão de ideias, elementos de cultura, tradições e hábitos sociais da comunidade; II - Oferecer mecanismos à formação e integração da comunidade, estimulando o lazer, a cultura e o convívio social; III - Prestar serviços de utilidade pública, integrando-se aos serviços de defesa civil, sempre que necessário (BRASIL, 1998).

Assim as dinâmicas de proximidade no rádio comunitário são costuradas por componentes sociais e identitários. Nesse sentido, Peruzzo (2005, p.78) destaca que "a mídia de proximidade caracteriza-se por vínculos de pertença, enraizados na vivência e refletidos num compromisso com o lugar e com a informação de qualidade". Enquanto parte da comunidade, essas rádios reconhecem as singularidades locais e associam sua linguagem com as especificidades cotidianas da população. É dessa forma que elas criam vínculos que vão além da associação dialógica emissora-ouvinte e têm "a possibilidade de mostrar, melhor que qualquer outro [meio de comunicação], a vida em determinadas regiões, municípios, cidades, vilas, bairros, zonas rurais, comunidades, etc" (Santos, 2010, p. 5).

Outra determinação da legislação explicita que a zona de alcance das rádios comunitárias não deverá ultrapassar o bairro ou a vila onde está instalada a emissora que, assim, poderá funcionar apenas com transmissores de baixa potência (até 25 watts) e altura máxima do sistema irradiante de trinta metros. Além disso, a licença para Serviço de Radiodifusão Comunitária é outorgada exclusivamente a fundações e associações comunitárias sem fins lucrativos.

\section{O panorama atual da radiodifusão comunitária no Brasil}

Desde as primeiras outorgas concedidas especificamente para rádios comunitárias a partir de 1999, o número de emissoras desse tipo cresceu exponencialmente na primeira década da legislação vigente, continuando em crescimento linear atualmente. O gráfico a seguir (Gráfico 1) mostra ano a ano a quantidade de rádios comunitárias existentes no Brasil e possibilita inferir que eram muitas as emissoras que funcionavam sem autorização antes da promulgação da lei, já que nos três primeiros anos de vigência da legislação foram certificadas novecentas e oitenta rádios comunitárias em todo o país. 
Gráfico 1 - Variação do número de emissoras comunitárias no Brasil (1999 - 2017)

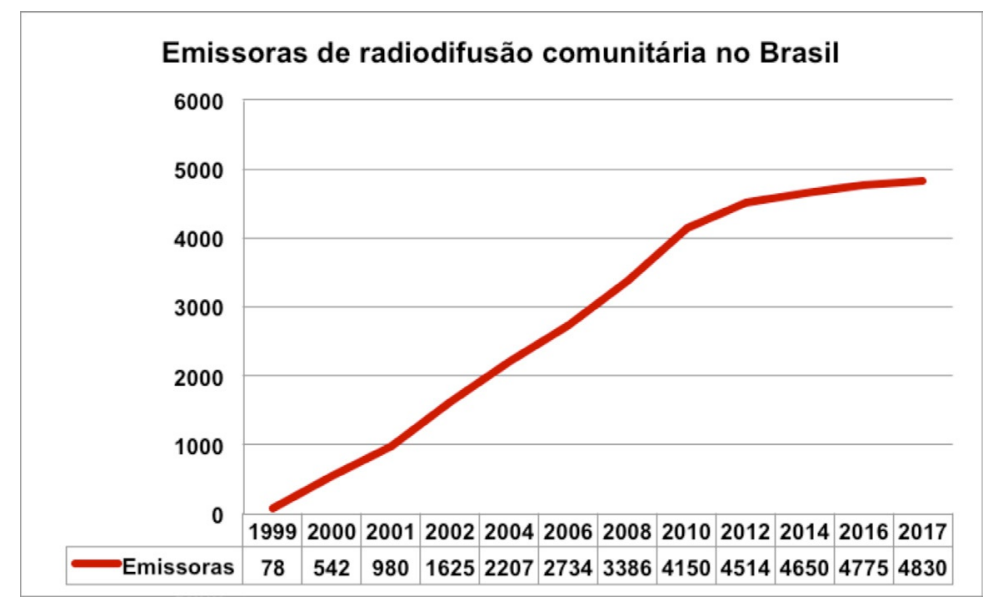

Fonte: Elaborado pelos autores com dados da Agência Nacional de Telecomunicações (2018)

Atualmente, as rádios comunitárias representam $51 \%$ do escopo da radiodifusão sonora brasileira. Oinfográfico a seguir (Figura1) permite visualizar os dados do Ministério de Ciência, Tecnologia, Inovações e Comunicações (MCTIC) quanto à divisão das 10.942 estações autorizadas entre comunitárias, comerciais e públicas ou educativas.

Figura 1 - Emissoras de rádio no Brasil segundo o tipo

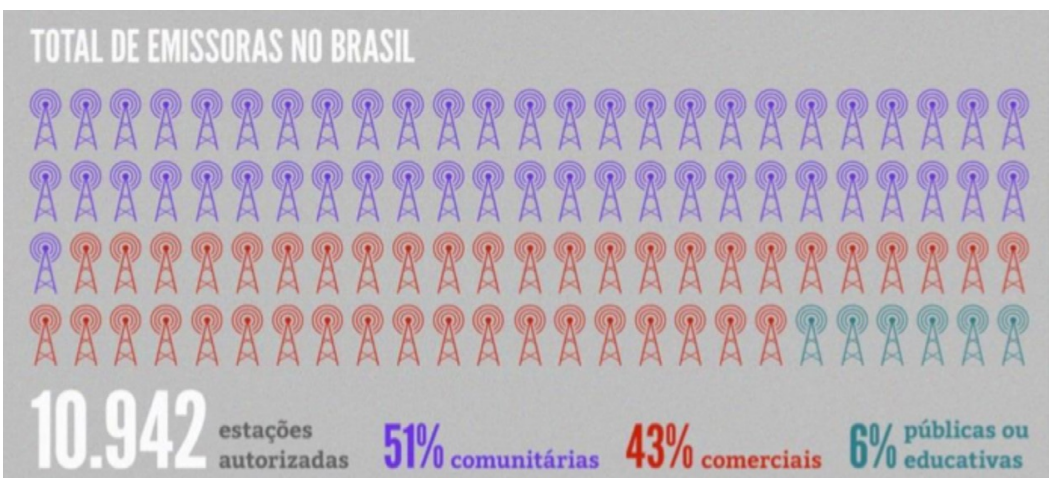

Fonte: Adaptado de Bertolotto e Gerab (2018).

Esse protagonismo das emissoras comunitárias se dá pelas ações governamentais para expandir esse tipo de rádio em pequenas cidades do país. Como funcionam com transmissores de baixa potência e normalmente têm na produção dos programas a participação da comunidade constituída, os custos 
de operação das rádios comunitárias são menores que os de emissoras de potência superior.

Desde 2011 o Governo Federal tem lançado editais específicos para rádios comunitárias dentro do Plano Nacional de Outorgas $^{1}$ da radiodifusão. O documento atual, que planeja a distribuição de outorgas entre 2018 e 2019, prevê o funcionamento de 697 novas rádios comunitárias abrangendo 340 municípios que ainda não possuem nenhuma emissora desse tipo em operação. O MCTIC espera que "ao final dos procedimentos de seleção, $77,61 \%$ dos municípios do país tenham pelo menos uma emissora de radiodifusão comunitária, o que representará um incremento de 6,1\% em relação à cobertura atual" (Brasil, 2018). O quadro a seguir dispõe a relação atual de outorgas de radiodifusão comunitária por municípios em cada região do Brasil:

Quadro 1 - Quantidade de outorgas de rádio comunitária por região do Brasil

\begin{tabular}{|l|c|c|c|c|}
\hline \multicolumn{1}{|c|}{ Região } & $\begin{array}{c}\text { Número total } \\
\text { de municípios }\end{array}$ & $\begin{array}{c}\text { Municípios com } \\
\text { emissora comunitária }\end{array}$ & $\begin{array}{c}\text { Em relação aos } \\
\text { municípios da região }\end{array}$ & $\begin{array}{c}\text { Em relação aos } \\
\text { municípios do país }\end{array}$ \\
\hline Centro-Oeste & 467 & 348 & $74,51 \%$ & $6,24 \%$ \\
\hline Sudeste & 1668 & 1251 & $75 \%$ & $22,45 \%$ \\
\hline Nordeste & 1794 & 1238 & $69 \%$ & $22,22 \%$ \\
\hline Norte & 450 & 297 & $66 \%$ & $5,33 \%$ \\
\hline Sul & 1191 & 849 & $71,28 \%$ & $15,42 \%$ \\
\hline Total & 5570 & 3983 & - & $71,6 \%$ \\
\hline
\end{tabular}

Fonte: Adaptado de Ministério de Ciência, Tecnologia, Inovações e Comunicações (2018).

Esses dados mostram a importância das rádios comunitárias para um país continental como o Brasil, com múltiplas características, identidades heterogêneas, regiões afastadas por milhares de quilômetros e desigualdades sociais que afetam modos de consumo - também midiáticos. As regiões que historicamente apresentam piores indicadores sociais no país - Norte e Nordeste - são as que proporcionalmente têm menos municípios com rádios comunitárias oficializadas. O mapa a seguir (Figura 2) apresenta o panorama atual das outorgas de serviço de radiodifusão comunitária em todos os estados brasileiros, demonstrando a concentração de emissoras nos estados de Minas Gerais ${ }^{2}$, São Paulo, Rio Grande do Sul, Bahia e Paraná.

1 'Os Planos Nacionais de Outorga (PNO's) são documentos que apresentam para a sociedade, de forma objetiva, todas as localidades que serão contempladas com a oportunidade de novas outorgas em cada um dos serviços de Radiodifusão" (MCTIC, 2018).

2 O estado de Minas Gerais concentra o maior número absoluto de rádios comunitárias por ser o estado brasileiro com mais municípios: 853 . Na sua capital, Belo Horizonte, surgiu aquela que pode ser considerada a primeira rádio comunitária do Brasil, a Rádio Favela, em 1981. 
Figura 2 - Distribuição de outorgas de rádios comunitárias por estado brasileiro

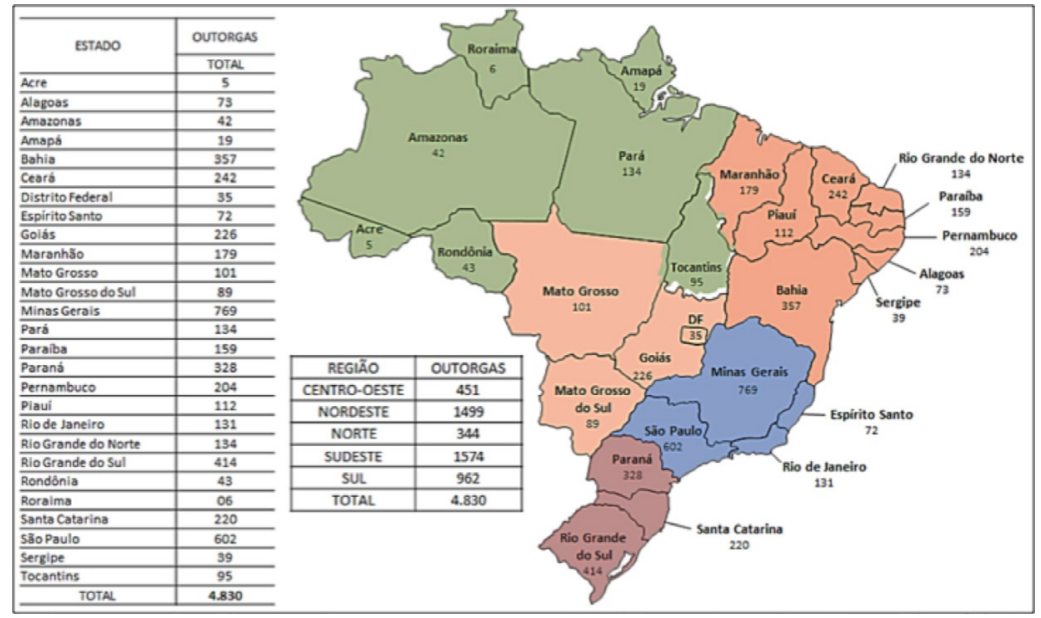

Fonte: Ministério de Ciência, Tecnologia, Inovações e Comunicações (2018).

Como será discutido adiante, as emissoras comunitárias têm a possibilidade de prestar um importante serviço para a população em seu entorno. Enquanto incluídas na comunidade, têm condições de informar melhor que qualquer outro meio sobre os acontecimentos relevantes para aqueles sujeitos, podem ser representativas ao executar programações musicais próximas do que as pessoas do lugar ouvem ou até mesmo utilizando sotaques, gírias e expressões próprias durante as locuções. Além disso, essas emissoras têm o compromisso de dar visibilidade aos serviços de utilidade pública e de estimular o lazer e a cultura local. Dessa forma é possível inferir a importância das rádios comunitárias em áreas isoladas e em lugares com pouco acesso a fontes de informação.

O Plano Nacional de Outorgas vigente pretende que, até o fim do ano de 2019 , todas as regiões do Brasil tenham pelo menos $70 \%$ dos seus municípios abrangidos por rádios comunitárias, como mostra o quadro a seguir.

Quadro 2 - Distribuição de outorgas de rádio comunitário PNO 2018/2019

\begin{tabular}{|l|c|c|c|}
\hline \multicolumn{1}{|c|}{ Região } & $\begin{array}{c}\text { Municípios } \\
\text { contemplados no PNO }\end{array}$ & $\begin{array}{c}\text { Estimativa de municípios } \\
\text { com emissora após o PNO }\end{array}$ & $\begin{array}{c}\text { Em relação ao total de } \\
\text { municípios da região após o PNO }\end{array}$ \\
\hline Centro-Oeste & 63 & 342 & $81,79 \%$ \\
\hline Sudeste & 202 & 1340 & $80,33 \%$ \\
\hline Nordeste & 209 & 1338 & $74,58 \%$ \\
\hline Norte & 46 & 322 & $71,55 \%$ \\
\hline Sul & 177 & 941 & $79 \%$ \\
\hline Total & 697 & 4323 & - \\
\hline
\end{tabular}

Fonte: Adaptado de Ministério de Ciência, Tecnologia, Inovações e Comunicações (2018). 
A estimativa é que 4.323 dos 5.570 municípios brasileiros tenham pelo menos uma emissora comunitária após o PNO, o que potencialmente representa importante ganho na democratização da radiodifusão sonora brasileira no que diz respeito à função social do meio.

Ainda que os avanços no sentido de oficializar as rádios comunitárias possam ser vistos através dos dados apresentados anteriormente, ainda existem emissoras do tipo funcionando clandestinamente. Isso se dá, sobretudo, pela burocracia para concessão de outorgas, pelos custos do cotidiano de produção e veiculação e pelas exigências legais de constituição associativa. Há ainda certa romantização das rádios clandestinas com base nos ideais das primeiras rádios livres brasileiras que surgiram no período de transição do regime ditatorial militar para a redemocratização lutando "pela abertura de canais não estatais e não comerciais privados, [...] pela quebra do monopólio simbólico do regime militar e do efetivo monopólio privado [e] por um modelo de comunicação de massa não "massificante”" (Andriotti, 2004, p. 68).

Não há qualquer estimativa da quantidade de emissoras de rádio funcionando ilegalmente no Brasil, porém, segundo dados da Anatel, em 2017 foram feitas 1.800 ações de fiscalização específicas para averiguar usos irregulares do espectro $^{3}$ ou a prestação de serviços de radiodifusão e de telecomunicações sem outorga. Como resultados dessas ações, 219 estações que funcionavam sem autorização tiveram suas transmissões interrompidas, sendo que 74 dessas tinham características técnicas sabidamente de rádio comunitário, usando transmissores com menos de 25 watts de potência e outras 61 não tiveram potência registrada.

O quadro a seguir (Quadro 3) esmiúça esses dados, corroborando para a constatação que o número de emissoras clandestinas ainda é alto no país e que há a possibilidade de expandir o serviço de radiodifusão comunitária nas áreas menos abrangidas pelo espectro, já que quase 4.0\% das emissoras ilegais que tiveram as transmissões interrompidas estavam localizadas nas regiões Norte e Nordeste. Outro número que chama atenção é o de estações interrompidas em Minas Gerais, ratificando que o estado potencialmente concentra ainda boa parte das emissoras ilegais em funcionamento no Brasil.

3 Usos irregulares do espectro são constatados quando determinada emissora transmite além da potência outorgada ou não respeita o limite protegido, gerando interferências em outras rádios e em serviços de radiofrequência, como a comunicação aeroportuária. 
Quadro 3 - Estações de rádio clandestinas interrompidas em 2017 no Brasil

\begin{tabular}{|l|c|c|c|c|}
\hline \multicolumn{1}{|c|}{ Estados } & $\begin{array}{c}\text { Emissoras com } \\
\text { menos de 25 watts }\end{array}$ & $\begin{array}{c}\text { Emissoras com } \\
\text { mais de 25 watts }\end{array}$ & $\begin{array}{c}\text { Emissoras sem } \\
\text { registro de potência }\end{array}$ & Total \\
\hline São Paulo & 4 & 10 & 6 & 20 \\
\hline $\begin{array}{l}\text { Rio de Janeiro e } \\
\text { Espírito Santo }\end{array}$ & 4 & 8 & 3 & 15 \\
\hline Paraná e Santa Catarina & 9 & 2 & 0 & 11 \\
\hline Minas Gerais & 23 & 32 & 3 & 58 \\
\hline Rio Grande do Sul & 4 & 1 & 8 & 13 \\
\hline Pernambuco, Alagoas e Paraíba & 3 & 1 & 3 & 7 \\
\hline $\begin{array}{l}\text { Goiás, Mato Grosso, Mato Grosso do } \\
\text { Sul e Tocantins }\end{array}$ & 8 & 7 & 4 & 19 \\
\hline Bahia e Sergipe & 3 & 1 & 16 & 20 \\
\hline Ceará, Rio Grande do Norte e Piauí & 5 & 8 & 1 & 14 \\
\hline Pará, Maranhão e Amapá & 7 & 12 & 6 & 25 \\
\hline Amazonas, Rondônia, Acre e Roraima & 4 & 1 & 10 & 15 \\
\hline Distrito Federal & 0 & 1 & 1 & 2 \\
\hline Total & 74 & 84 & 61 & 219 \\
\hline
\end{tabular}

Fonte: Adaptado de Agência Nacional de Telecomunicações (2018).

Quando a fiscalização da Anatel constata a existência de emissora que faz uso irregular do espectro ou funciona sem autorização, imediatamente os aparelhos são apreendidos e os responsáveis por manter as atividades ilegais respondem por crime previsto na chamada Lei Geral das Telecomunicações. Essa legislação, sancionada em 1997, define como clandestina "a atividade desenvolvida sem a competente concessão, permissão ou autorização de serviço, de uso de radiofreqüência e de exploração de satélite" (Brasil, 1997) e prevê pena de até seis anos de prisão e multa de dez mil reais para os infratores.

Embora tenham sido intensificadas nos últimos anos, as ações de fiscalização ainda apresentam algumas fragilidades por serem, em grande parte, dependentes de denúncias e dificultadas pela rápida comunicação entre os operadores das rádios ilegais. Os gestores de emissoras recémlegalizadas apontam o burocrático processo de concessão de outorgas como o principal motivo da existência de tantas rádios clandestinas, como pontua o coordenador de uma emissora oficializada no interior de Minas Gerais depois de anos funcionando ilegalmente: "Tem sete anos que estamos correndo atrás da legalização. É muita documentação que precisa e muito trabalho que deve ser feito. Por isso que existe tanta rádio pirata. Muitos desistem de tentar ou nem tentam por saber que é difícil" (Ezequiel, 2016, s.p). De fato, a Anatel impõe uma série de condições para conceder outorgas de operação dos serviços de 
radiodifusão, porém muitas das exigências são para evitar interferências em outros serviços que usam radiofrequência, como o controle de espaço aéreo. $\mathrm{O}$ atual PNO para rádios comunitárias objetiva facilitar os processos de outorga em cidades que ainda não possuem o serviço, expandindo e fortalecendo o serviço de radiodifusão em pequenas cidades.

Através do estudo de caso realizado, com resultados expostos a seguir, foi possível de entender as especificidades das rádios comunitárias que funcionam de forma clandestina no interior do Brasil, evidenciado características de programação, monetização, difusão e a busca pela legalização no panorama atual.

\section{Especificidades do rádio comunitário no Brasil: estudo de caso}

O estudo de caso continua sendo um método bastante explorado e eficiente para pesquisas em comunicação porque investiga, empiricamente, "um fenômeno contemporâneo dentro de seu contexto da vida real” (Yin, 2001, p. 32). Em função das observações pretendidas para a presente pesquisa, "o mais promissor para nossas dúvidas é o exame acurado de um caso singular" (Braga, 2011, p. 11). Além disso, a possibilidade de usar múltiplos métodos como forma de analisar o fenômeno facilita que se chegue a compreensões válidas para as questões levantadas previamente. Para a realização deste estudo foram feitas visitas à emissora escolhida, escuta sistematizada da programação e entrevista semi-estruturada com o idealizador da rádio.

Partindo deste preâmbulo, a escolha da Rádio Paraíso para este estudo se justifica pela consolidação da emissora, funcionando clandestinamente há 17 anos, por estar localizada em uma pequena cidade do interior de Minas Gerais, por sua aceitação entre a população local e pela especificidade de não haver nenhuma emissora legalizada na cidade. O município de Diogo de Vasconcelos, onde está sediada a Rádio Paraíso, tem população atualmente estimada em 3.814 habitantes e está localizado a 165 quilômetros da capital de Minas Gerais. É uma localidade essencialmente rural, com a agricultura e pecuária como principais atividades e com mais de $70 \%$ da população vivendo fora da área urbana (Instituto Brasileiro de Geografia e Estatística, 2010; 2018).

A trajetória da Rádio Paraíso começou no início dos anos 200o com um grupo de amigos entusiastas da radiodifusão. Um desses idealizadores da emissora mantém a rádio em funcionamento até hoje, juntamente com sua esposa. Em entrevista concedida no âmbito deste estudo, o idealizador, que preferiu não se identificar ${ }^{4}$, explica que a emissora não é a primeira criada por ele, mas que, por ser um aficionado pelo meio radiofônico, já iniciou muitas outras emissoras clandestinas: "A Rádio Primeira Capital, localizada em Passagem de Mariana, por exemplo, é uma que eu também iniciei. Na época foi de maneira ilegal, mas

4 Para preservar o anonimato, o coordenador da Rádio Paraíso será identificado pelo pseudônimo Antônio Silva quando suas falas aparecerem integralmente no artigo. 
hoje ela possui concessão e funciona como rádio comunitária" (Antônio Silva, entrevista pessoal $\mathrm{n}^{\circ} 1$. Setembro de 2018).

O estúdio improvisado da Rádio Paraíso funciona em um pequeno cômodo na casa do idealizador (Foto 1), com todos os equipamentos necessários para transmissão adquiridos por ele. As instalações e reparos que sejam fundamentais também são feitos pelo coordenador da emissora, que ainda se apresenta como técnico em eletrônica.

Foto 1 - Estúdio de transmissão da Rádio Paraíso

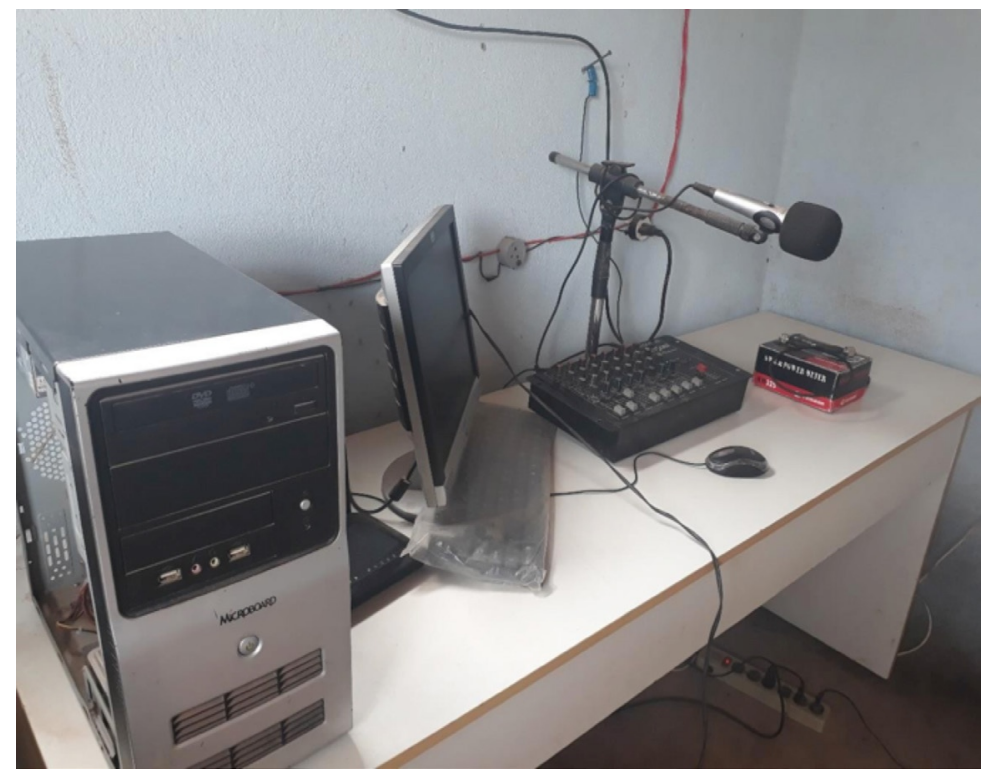

Fonte: Fotografia de Eliene Santos (2018).

O sinal da Rádio Paraíso não interfere na transmissão de outras emissoras porque utiliza a frequência $87,9 \mathrm{FM}$ do espectro, parte ainda não outorgada para nenhuma emissora no Brasil ${ }^{5}$, um dos motivos de a rádio ainda não ter sido alvo de nenhuma investigação da Anatel. A antena foi instalada no quintal da casa (Foto 2), que está localizada em uma parte alta da cidade, o que facilita ainda mais a transmissão do sinal. Não foi possível obter informações do alcance da rádio, mas, segundo Silva, abrange toda a cidade e regiões próximas.

5 Os canais com sintonia abaixo de $88 \mathrm{MHz}$ serão outorgados a partir do processo de migração das emissoras AM para FM que está acontecendo no Brasil. Desde 2013, das 1.781 emissoras comerciais que operavam em AM no Brasil, 1.622 solicitaram a mudança de frequência e 650 delas já estão operando na faixa de FM. As rádios comunitárias não serão atingidas diretamente pela mudança. 
Foto 2 - Torre de transmissão da Rádio Paraíso

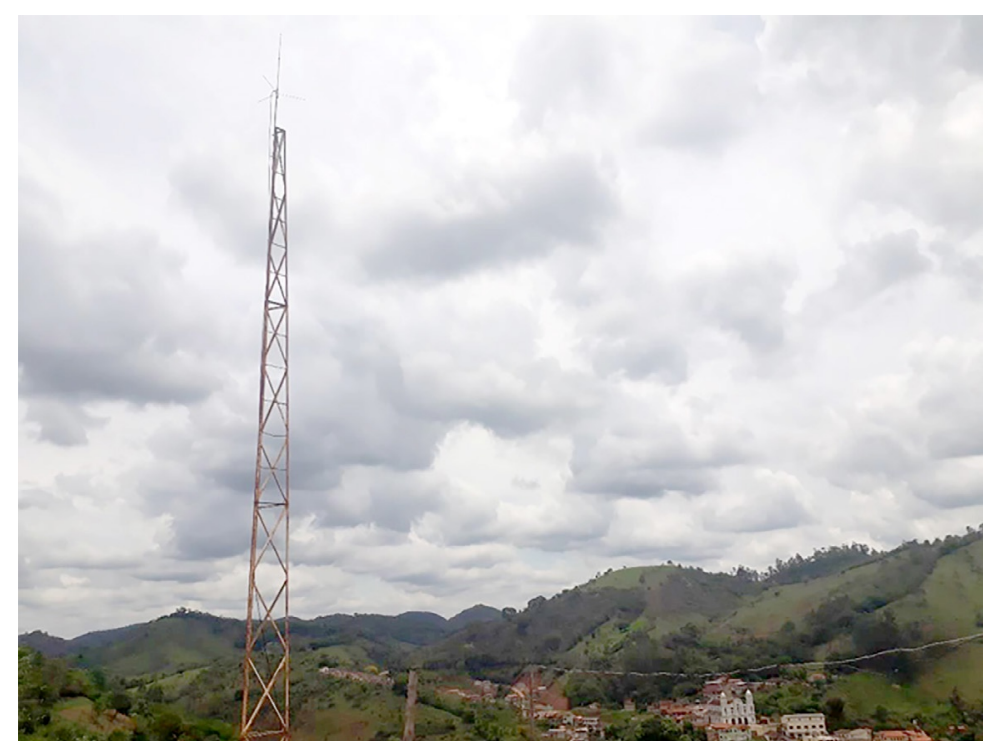

Fonte: Fotografia de Eliene Santos (2018)

A radiodifusão local e comunitária é de grande importância para a população das pequenas localidades como Diogo de Vasconcelos porque, conforme evidencia Raddatz (2011), em muitas cidades do interior do país o rádio exerce uma posição de centralidade em diversos aspectos da vida social, anunciando objetos perdidos, campanhas de vacinação, horários de ônibus, veiculando notas de falecimentos, convites para missas e eventos da comunidade. Soares, citada por Bertolotto e Gerab (2018, s.p), complementa afirmando que o rádio "entra pelos igarapés até as comunidades ribeirinhas. Nas casas de farinha, o som é do radinho. Ele fortalece nossa identidade e traz conhecimento. $\mathrm{Na}$ Amazônia, ele é tão primordial como o WhatsApp para as pessoas da cidade". É dessa forma que o local, enquanto lugar de construção social compartilhada de relações estabelecidas entre pessoas de uma mesma comunidade, "coloca em forma o mundo da vida diária, sendo ele próprio fundador da relação com o mundo do indivíduo, mas igualmente da relação com o outro, da construção comum do sentido que faz o vínculo social" (Bourdin, 2001, p. 36).

A rádio comunitária desde o começo concebe os valores sociais do lugar em que está inserida, já que surge da comunidade, com características partilhadas com a população, retratando a realidade com base nos diferentes componentes identitários. Esse tipo de emissora se configura também como prestadora de serviços e tem forte participação na busca pela resolução de problemas sociais das suas comunidades. É dessa forma que o rádio comunitário, assim como 
o local, cria um laço de "afinidade com o ouvinte que nele se enxerga e se vê representado pela linguagem, pelas temáticas e pela possibilidade de ouvir seu nome, o nome do seu amigo, da localidade onde mora ou dos lugares que frequenta" (Raddatz, 2011, p. 1).

O idealizador da rádio confirma que a emissora divulga ações da prefeitura da cidade e presta serviços mais diretos à população, veiculando notas de falecimento, informações de campanhas assistenciais e documentos perdidos: "Quando alguém perde o documento a gente noticia aqui. Se a pessoa precisa de uma cadeira de rodas a gente pede também e logo ela consegue a doação de uma. Falamos também de datas importantes, como as de campanhas de vacinação" (Antônio Silva, entrevista pessoal $\mathrm{n}^{\circ} 1$. Setembro de 2018).

Dessa forma, a relação da Rádio Paraíso com a população é bastante forte desde o começo, tanto que a emissora passou a ser entendida como parte da cidade, sendo conhecida entre os ouvintes apenas como Rádio Diogo. Além disso, a população participa ativamente da única rádio da cidade, que disponibiliza diferentes canais para que os ouvintes entrem em contato. Quadros e Lopez (2013) justificam que a interatividade no rádio se modifica quando o meio se apropria de elementos tecnológicos como forma de mediação, "passando a considerar outros ambientes onde o rádio está presente: seu site institucional, sites de redes sociais, aplicativos para celular, programas de bate-papo virtual, entre outras" (p. 2).

Nascida quando as emissoras tradicionais começaram a se apropriar de outros elementos e plataformas digitais, a Rádio Paraíso tem página na internet ${ }^{6}$ onde também transmite seus conteúdos ao vivo e disponibiliza o aplicativo de mensagens WhatsApp como forma de interação com a audiência. Segundo o idealizador da emissora, as pessoas interagem principalmente com pedido de músicas, "mas também entram em contato para pedir para noticiar algo como uma nota de falecimento, assim todos ficam sabendo o horário do sepultamento e local" (Antônio Silva, entrevista pessoal no ${ }^{\circ}$. Setembro de 2018).

Como rádio ilegal a emissora não poderia receber nenhum tipo de patrocínio ou apoio cultural, já que não se trata de entidade constituída. Porém, três empresas locais anunciam na programação da rádio o que, segundo Silva, não é suficiente para manter a emissora no ar.

Recebemos um dinheirinho que utilizamos para alguma coisinha na rádio. É pouquinha coisa, mas ajuda em algo. Mas eu não me importo em lucrar não. Eu gosto muito de rádio, por isso, eu me esforço ao máximo para mantê-la em funcionamento com o meu próprio dinheiro. (Antônio Silva, entrevista pessoal $\mathrm{n}^{\circ} 1$. Setembro de 2018).

Há em tramitação no congresso federal projeto que altera Lei Geral de Telecomunicações e dá às empresas que contratam propaganda em rádios e

6 www.radioparaisofm.net 
TVs ilegais as mesmas sanções previstas aos responsáveis pela operação dessas emissoras.

A Lei que regulamenta as rádios comunitárias deixa claro que a constituição dessas emissoras não deve prever lucro e que "as prestadoras do Serviço de Radiodifusão Comunitária poderão admitir patrocínio, sob a forma de apoio cultural, para os programas a serem transmitidos, desde que restritos aos estabelecimentos situados na área da comunidade atendida" (Brasil, 1998). As definições de apoio cultural, entretanto, são controversas, o que possibilita que essa regra seja muitas vezes desrespeitada pelas rádios comunitárias.

Questionado sobre as perspectivas de legalização da Rádio Paraíso, Silva explica que tem interesse em fazer da emissora uma rádio comunitária outorgada, porém, assim como discutido anteriormente, ele também considera o processo de autorização burocrático: "Dá muito trabalho. São muitos documentos, relatórios. É uma papelada que eles exigem. Enquanto não providenciamos tudo, vamos dando continuidade aos nossos programas. Um dia a licença sai” (Antônio Silva, entrevista pessoal nº 1 . Setembro de 2018).

A rádio segue funcionando com uma programação bastante diversificada, centrada em músicas, prestação de serviços e informações cotidianas da cidade de Diogo de Vasconcelos. Em seguida, será apresentada a programação da emissora como forma de evidenciar essa diversidade e as singularidades da rádio.

\subsection{A programação da Rádio Paraíso}

A programação de uma rádio se constitui a partir de diversos critérios que orientam as principais características da emissora. Josep Maria Martí (2004) entende que "as características específicas da programação geram na prática algumas determinadas estratégias de programação vinculadas a determinados condicionamentos internos e externos na elaboração e difusão do produto (radiofônico)" (Martí, 2004, p. 31). Segundo Ferraretto (2014, p. 70), a programação "é o conjunto organizado dos conteúdos veiculados por uma emissora de rádio, sejam estes jornalísticos, de entretenimento, de serviços, publicitários e/ou musicais, produzidos conforme o formato adotado pela emissora". Nessa perspectiva, Martí ainda evidencia que "a programação também pode ser definida como uma arte que reúne os programas e os públicos a que são destinados, o que supõe que se coloque em prática uma técnica de duas articulações: a dos tempos de emissão com a dos tempos sociais" (Martí, 2004, p. 33).

Assim, na construção da programação de uma emissora comunitária é preciso levar em conta fatores externos como especificações legais e técnicas, as características do lugar em que estão inseridas, os tempos sociais, que redimensionam modos de escuta e interação, além das singularidades e demandas do seu ouvinte. O quadro de programação da Rádio Paraíso é 
constituído em grande parte de músicas, sobretudo do gênero sertanejo, mas programas de entretenimento e informativos também têm espaço na grade que é descrita no quadro a seguir (Quadro 4).

Quadro 4 - Grade de programação da Rádio Paraíso

\begin{tabular}{|l|l|}
\hline \multicolumn{1}{|c|}{ Horário } & \multicolumn{1}{c|}{ Programa } \\
\hline $6 \mathrm{~h}$ às $8 \mathrm{~h}$ & Recanto Sertanejo \\
\hline $8 \mathrm{~h}$ às $10 \mathrm{~h}$ & Ceilândia Brasília \\
\hline $10 \mathrm{~h}$ às $12 \mathrm{~h}$ & Bom Dia Cidade \\
\hline $12 \mathrm{~h}$ às $14 \mathrm{~h}$ & Programa Gospel \\
\hline $14 \mathrm{~h}$ às $17 \mathrm{~h}$ & Show da Cidade \\
\hline $17 \mathrm{~h}$ às $19 \mathrm{~h}$ & Trem Caipira (sertanejo raiz) \\
\hline $19 \mathrm{~h}$ às $20 \mathrm{~h}$ & Voz do Brasil (retransmissão de Brasília) \\
\hline $20 \mathrm{~h}$ às $22 \mathrm{~h}$ & Eu de Cá, Você de Lá \\
\hline $22 \mathrm{~h}$ às $6 \mathrm{~h}$ & Programação musical variada (automática) \\
\hline
\end{tabular}

Fonte: Elaborado pelos autores com dados da pesquisa.

Como se trata de uma rádio clandestina, a Paraíso não precisaria se preocupar com especificações legais, porém a veiculação da "Voz do Brasil", obrigatória para todas as rádios legalizadas, mostra o interesse da emissora em se tornar uma rádio oficializada.

\section{Conclusões}

As rádios comunitárias brasileiras nasceram clandestinas, com características ideológicas e objetivo de dar visibilidade a uma parcela da população invisibilizada pelos meios de comunicação tradicional. A cultura produzida nas comunidades, os abusos das operações policiais nas favelas, a violência, os projetos sociais, as informações importantes para a população de lugares marginalizados eram simplesmente desprezadas pelos grandes meios. Dessa forma, mesmo atuando na clandestinidade, as rádios comunitárias passaram a ter importante função social quando inserida nesses lugares.

A legalização dessas rádios veio após quase vinte anos de funcionamento clandestino, quando o governo federal instituiu regras para a criação e atividade das emissoras comunitárias. Embora as determinações tenham seguido as configurações de programação e serviço já experimentadas pelas emissoras então ilegais, o processo de instalação hoje é considerado burocrático, fazendo com que ainda existam muitas rádios funcionando ilegalmente no Brasil.

Através do estudo de caso com base na Rádio Paraíso foi possível confirmar que a morosidade do processo de outorga é um dos motivos que levam algumas rádios a se manterem na ilegalidade. Ainda assim, foi possível atestar a importante função social que as rádios comunitárias desempenham. A única 
emissora de Diogo de Vasconcelos desempenha um papel informativo essencial na vida dos quase quatro mil moradores da cidade. É através da rádio ilegal que a população se informa sobre campanhas de vacinação, serviços da prefeitura e eventos culturais.

A caracterização da Rádio Paraíso como comunitária e não como pirata no presente estudo parte da interpretação que o idealizador não tem intenção de obter lucro através das atividades da emissora. Tendo começado como um hobby para um grupo de amigos aficionados por radiodifusão, os atuais mantenedores da emissora têm a consciência que há anos ela deixou de ser um passatempo, contando com um público fiel que interage com a emissora e se vê representado nela.

Mesmo diante do risco de ter a emissora fechada pelos órgãos de fiscalização, durante os dezessete anos de funcionamento da rádio a possibilidade de interrupção do trabalho nunca foi cogitada. Não interferindo no sinal de nenhuma outra rádio, a única emissora de Diogo de Vasconcelos nunca sofreu nenhuma investigação, ainda assim, há a intenção de legalizar a Rádio Paraíso.

As características heterogêneas e as desigualdades sociais tão evidentes entre as regiões brasileiras fazem com o rádio e, em especial, as emissoras comunitárias, sejam relevantes para informar, educar, aproximar os sujeitos, reforçar tradições e costumes específicos das pequenas cidades ou das comunidades marginalizadas nos grandes centros urbanos.

Como futuro desdobramento deste trabalho, é intenção dos autores esmiuçar a importância da Rádio Paraíso para a população de Diogo de Vasconcelos através de pesquisa de recepção com os ouvintes da emissora clandestina.

\section{Referências}

Agência Nacional de Telecomunicações. (2018). Relatório Anual 2017 Anatel. Brasília: Agência Nacional de Telecomunicações. Disponível em https://bit.ly/2EwvUQ9.

Andriotti, C. D. (2004). O movimento das Rádio Livres e Comunitárias e a democratização dos meios de comunicação no Brasil. (Dissertação de Mestrado).

Bertolotto, R. \& Gerab, M. (2018, julho). País sem sintonia: depois de integrar o Brasil por décadas, o rádio vive mudanças que podem provocar o efeito contrário. UOL, 2018. Disponível em https://tab.uol.com.br/radio/\#pais-sem-sintonia.

Bourdin, A. (2001). A questão local. Rio de Janeiro: DP\&A.

Braga, J. L. (2011). A prática da pesquisa em Comunicação: abordagem metodológica como tomada de decisões. E-compós, 14(1). Disponível em https://bit.ly/2GKcgTa.

Brasil. Lei $n^{\circ}$ 9.472. (1997). Dispõe sobre a organização dos serviços de telecomunicações, a criação e funcionamento de um órgão regulador e outros aspectos institucionais, nos termos da Emenda Constitucional no 8, de 1995. Brasília: Diário Oficial da União. Disponível em http://www.planalto.gov.br/CCIVIL_03/LEIS/L9472.htm.

Brasil. Lei no 9.612. (1998). Institui o Serviço de Radiodifusão Comunitária e dá outras providências. Brasília: Diário Oficial da União. Disponível em http://www.planalto.gov.br/ ccivil_03/leis/L9612.htm.

Ezequiel, Wôlmer. (2016, novembro 07). Coronel Fabriciano terá sua primeira rádio comu- 
nitária. Diário do Aço. Disponível em https://bit.ly/2Ntqzfr.

Ferraretto, L. A. (2014). Rádio: Teoria e prática. São Paulo: Summus.

Freitas, V. H. M. Espaço sertanejo: A música sertaneja cantando o espaço geográfico. (2017). (Dissertação de Mestrado). Disponível em https://bit.ly/2IEuAif.

Instituto Brasileira de Geografia e Estatística. (2010). Censo Demográfico 2010. Rio de Janeiro: Instituto Brasileira de Geografia e Estatística.

Instituto Brasileira de Geografia e Estatística. (2018). População estimada: Estimativas da população residente com data de referência $1^{\circ}$ de julho de 2018. Rio de Janeiro: Instituto Brasileira de Geografia e Estatística. Disponível em: https://bit.ly/2NuBR2T.

Martí, J. M. (2004). La programación radiofónica. In M. P. Martínez-Costa \& E. Moreno, Programación radiofónica - Arte y Técnica Del diálogo entre la radio y su audiencia. Barcelona: Ariel.

Ministério da Ciência, Tecnologia, Inovações e Telecomunicações. (2018). Plano Nacional de Outorgas 2018/2019 - Radiodifusão Comunitária. Brasília: Ministério da Ciência, Tecnologia, Inovações e Telecomunicações. Disponível em https://bit.ly/2tCd6ZF.

Peruzzo, C. M. K. (2005). Mídia regional e local: aspectos conceituais e tendências. Comunicação \& Sociedade, 43, 67-84.

Peruzzo, C. M. K. (2010). Rádios Comunitárias no Brasil: da desobediência civil e particularidades às propostas aprovadas na CONFECOM. Anais do XIX Encontro Anual da Compós, Rio de Janeiro.

Pesavento, S. J. (2006). Fronteiras culturais em um mundo planetário - paradoxos da(s) identidade(s) sul-latino-americana(s). Revista del CESLA, 8, 9-19. Disponível em: https:// bit.ly/2SrehFo.

Quadros, M. R. \& Lopez, D. C. (2013). A interatividade no rádio hipermidiático e expandido: uma proposta de classificação. Anais do XXXVI Congresso Brasileiro de Ciências da Comunicação, Manaus - AM. São Paulo: Intercom.

Raddatz, V. L. S. (2011). Rádio AM «avisa»: uma expressão da cultura local. In: L. Klöckner \& N. Prata (orgs.), Mídia sonora em 4 dimensões: $1^{\mathrm{a}}$ ouvintes e falantes, $2^{\mathrm{a}}$ memória política, $3^{\text {a }}$ programas de rádio, $4^{\text {a }}$ tecnologia e futuro. Porto Alegre: EdiPUCRS.

Santos, M. C. (2010). A importância do noticiário local de rádio em tempos de globalização: uma análise da opinião dos ouvintes da Rádio Itatiaia. (Dissertação de Mestrado).

Sousa, S. S. G. (1997). Rádios ilegais: da legitimidade à democratização das práticas. (Dissertação de Mestrado). Disponível em: https://bit.ly/2Tkju68.

Yin, R. K. (2001). Estudo de caso: planejamento e métodos. 2. ed. Porto Alegre: Bookman. 